\title{
Everolimus Tablets for Oral Suspension
}

National Cancer Institute

\section{Source}

National Cancer Institute. Everolimus Tablets for Oral Suspension. NCI Thesaurus. Code C102880.

Tablets for oral suspension containing everolimus, a derivative of the natural macrocyclic lactone sirolimus, with immunosuppressive and antineoplastic activities. After suspension of the everolimus tablets in water and oral administration, this agent inhibits the activation of the serine/threonine kinase mammalian target of rapamycin (mTOR) by binding to mTOR's cytosolic receptor immunophilin FK Binding Protein-12 (FKBP-12). Inhibition of the mTOR complex may result in the inhibition of the phosphatidylinositol 3 kinase/Akt/mT OR pathway and an inhibition in the expression of vascular endothelial cell growth factor (VEGF) and hypoxia-inducible factor. Ultimately, this may result in decreased tumor cell proliferation and tumor ang iogenesis. This pediatric formulation can dissolve easily in a small volume of water making it easier to swallow and is available in smaller dose increments thereby allowing for greater dosing flexibility. 